\title{
Effect of resin-modified glass-ionomer cement lining and composite layering technique on the adhesive interface of lateral wall
}

\author{
Larissa Marinho AZEVEDO, Leslie Carol CASAS-APAYCO, Carlos Andres VILLAVICENCIO ESPINOZA, Linda WANG, \\ Maria Fidela de Lima NAVARRO, Maria Teresa ATTA
}

Department of Restorative Dentistry, Endodontics and Dental Materials, Bauru School of Dentistry, University of São Paulo, Bauru, SP, Brazil.

Corresponding address: Maria Teresa Atta - Al Dr Octávio Pinheiro Brisolla, 9-75 - 17012-901 - Bauru - SP - Brasil - Phone: +551432358352 - Fax: +551432358323 - e-mail: tereatta@usp.br

Submitted: November 23, 2014 - Modification: April 19, 2015 - Accepted: April 27, 2015

\section{ABSTRACT}

\begin{abstract}
Tnterface integrity can be maintained by setting the composite in a layering technique 1 and using liners. Objective: The aim of this in vitro study was to verify the effect of resin-modified glass-ionomer cement (RMGIC) lining and composite layering technique on the bond strength of the dentin/resin adhesive interface of lateral walls of occlusal restorations. Material and Methods: Occlusal cavities were prepared in 52 extracted sound human molars, randomly assigned into 4 groups: Group $2 \mathrm{H}$ (control) - no lining + two horizontal layers; Group 4O: no lining + four oblique layers; Group V-2H: RMGIC lining (Vitrebond) + two horizontal layers; and Group V-4O: RMGIC lining (Vitrebond) + four oblique layers. Resin composite (Filtek Z250, 3M ESPE) was placed after application of an adhesive system (Adper ${ }^{\mathrm{TM}}$ Single Bond 2, 3M ESPE) dyed with a fluorescent reagent (Rhodamine B) to allow confocal microscopy analysis. The teeth were stored in deionized water at $37^{\circ} \mathrm{C}$ for 24 hours before being sectioned into $0.8 \mathrm{~mm}$ slices. One slice of each tooth was randomly selected for Confocal Laser Scanning Microscopy (CLSM) analysis. The other slices were sectioned into $0.8 \mathrm{~mm} \times 0.8 \mathrm{~mm}$ sticks to microtensile bond strength test (MPa). Data were analyzed by two-way ANOVA and Fisher's test. Results: There was no statistical difference on bond strength among groups ( $p>0.05)$. CLSM analysis showed no significant statistical difference regarding the presence of gap at the interface dentin/ resin among groups. Conclusions: RMGIC lining and composite layering techniques showed no effect on the microtensile bond strength and gap formation at the adhesive interface of lateral walls of high C-factor occlusal restorations.
\end{abstract}

Keywords: Composite resins. Glass-ionomer cements. Dental bonding.

\section{INTRODUCTION}

Although resin-based restorative materials have been widely used in contemporary restorative dentistry $^{3}$, the polymerization shrinkage, inherent characteristic of dental composites, induces stress during the curing of the resin composites, and this is still a great drawback $k^{5,17,33}$.

It is widely accepted that volumetric contraction and solidification during the polymerization process of restorative composites in combination with bonding to the hard tissue results in stress transfer and inward deformation of the cavity walls of the restored tooth ${ }^{21}$. The shrinkage stress is transferred to the surrounding tooth structure, since it restricts the volumetric changes ${ }^{18,26}$. When shrinkage stress overcomes the bond strength to the cavity walls, the marginal seal of adhesive composite restorations is lost, resulting in gap failures at the tooth-composite interface. Once the bond between restoration and tooth fails, microleakage of oral fluids, bacteria, molecules, and ions occurs at the tooth-composite interface $7,8,12,19$ resulting in marginal leakage, postoperative sensitivity, marginal discoloration, recurrent caries and consequent pulp pathology $4,13,15,19$.

The concept of the cavity configuration factor or $\mathrm{C}$-factor (expressed as the ratio between bonded 
and free surfaces of the specimen) and restoration placement techniques are widely recognized as major factors in determining shrinkage stress ${ }^{9,16,23}$.

Clinical strategies were suggested to minimize the development of stresses at the cavity margins and gap formation. Glass-ionomer cements (GICs) and resin-modified glass-ionomer cements (RMGIC) have been utilized as liners ${ }^{4,29}$ to provide the stressbuffering capacity for reducing the contraction stress and gap formation at the dentin/resin adhesive interface ${ }^{27}$. Additionally, a reduced amount of resin composite is necessary to fill the cavity, which allows less contraction stress ${ }^{21}$.

The magnitude of stress generated during polymerization of resin composite on the dentin/ resin adhesive interface can be decreased by the layering insertion technique that reduces the cavity configuration factor and the stress of polymerization shrinkage at the tooth composite interface by permitting the stress-relieving flow of composite from the unbounded surface towards the bonded surface ${ }^{20}$. Incremental layering, horizontal or oblique, is the standard of care for placement of resin composites in cavity preparations exceeding $2 \mathrm{~mm}^{32}$, by virtue of the sufficient exposure of the entire increment to the curing light, as well as the reduction of the volume of the contracting material 1,15,16,22-24,28.

Many studies have reported the influence of resin-modified glass-ionomer cement lining and composite layering techniques on the microleakage and bond strength ${ }^{23}$, influence of C-factor and composite layering technique on microtensile bond strength to dentin ${ }^{14}$, the effects of cavity size and incremental technique on microtensile bond strength of resin composite in Class I cavities ${ }^{15}$. However, these effects were mostly evaluated for pulpal walls and there is a lack of information on how they influence the adhesive interface of lateral walls.

Thus, considering that interface integrity can be preserved by the composite layering technique and by the use of a liner, the aim of this in vitro study was to analyze the effect of resin-modified glass-ionomer cement lining and composite layering technique on the bond strength of the dentin/ resin adhesive interface of lateral walls of occlusal restorations. The hypothesis tested was that the use of resin-modified glass-ionomer cement lining and composite layering technique affect dentin adhesive strength and gap formation on lateral walls.

\section{MATERIAL AND METHODS}

Materials used in this study and their compositions are listed in Figure 1.

Fifty-two freshly extracted human non carious third molars were obtained under a protocol approved by the Ethics Committee of the Bauru School of Dentistry, University of São Paulo (146/2009/FOB).

The occlusal surface was ground flat to facilitate the establishment of the dimensions of the cavity preparation and to remove the occlusal enamel. Class I cavities (Type 1 - to groups V-2H and V-4O: $4.5 \mathrm{~mm}$ deep, $3 \mathrm{~mm}$ wide, $5 \mathrm{~mm}$ long; Type 2 - to groups $2 \mathrm{H}$ and 40 : $4.0 \mathrm{~mm}$ deep, $3 \mathrm{~mm}$ wide, 5 $\mathrm{mm}$ long) were prepared in dentine using a highspeed handpiece with a cylindrical carbide bur (56; KG Sorensen, São Paulo, SP, Brazil), those carbide bur were changed every 5 preparations made. After these procedures, the teeth were randomly assigned to be restored according to the following 4 groups $(n=13)$.

Group $2 \mathrm{H}$ : no lining and 2 horizontal composite layers (control)

Group 40: no lining and 4 oblique composite layers

Group V-2H: RMGIC and 2 horizontal composite layers

Group V-4O: RMGI and 4 oblique composite layers

Specimens in groups $2 \mathrm{H}$ and 40 were etched with $37 \%$ phosphoric acid (Dentsply, Rio de Janeiro, RJ, Brazil) for 15 seconds in dentin, then rinsed and dried with absorbent paper. Adper Single Bond 2 (3M ESPE Dental Products, St. Paul, MN, USA) was applied in two consecutive layers and after 15 seconds, gently air dried to allow evaporation of the solvent prior to 10 seconds polymerization with LED (Optilight LD Max Gnatus, Ribeirão Preto, $\mathrm{SP}$, Brazil) at $500 \mathrm{~mW} / \mathrm{cm}^{2}$, measured by a specific radiometer. The cavity was filled with Filtek Z250 (Universal Restorative ${ }^{\circledR}$, shade A3 - 3M ESPE Dental Products, St. Paul, MN, USA). In group $2 \mathrm{H}$, the resin composite was inserted in two $(2 \mathrm{~mm}$ ) horizontal layers cured for $20 \mathrm{~s}$ each. In group 40 the resin composite was applied in four $(2 \mathrm{~mm}$ ) oblique layers. Specimens in groups $\mathrm{V}-2 \mathrm{H}$ and $\mathrm{V}-4 \mathrm{O}$ were lined with a $0.5 \mathrm{~mm}$ resin-modified glass-ionomer cement (Vitrebond, 3M ESPE Dental Products, St. Paul, MN, USA) on the pulpal floor, applied with a calcium hydroxide applicator. After lining, bonding and restorative procedures were performed as described for groups $2 \mathrm{H}$ and $4 \mathrm{O}$, respectively.

The specimens were stored at $37^{\circ} \mathrm{C}$ in deionized water for $24 \mathrm{~h}$ and sectioned buccolingually into $0.8 \mathrm{~mm}$ thick slices with a diamond disk (Extec Corp., Enfield., CT, USA) under water cooling in an Isomet Low Speed Saw (Buehler, Lake Bluff, IL, USA). One slice of each tooth was randomly selected for analysis of the buccal wall by Confocal Laser Scanning Microscopy (Leica TCS SPE, Mannheim, Germany, DMI 4000B with diode laser excitation of $532 \mathrm{~nm}$ ) to assess the presence of gaps. To allow confocal microscopy analysis, Adper Single Bond 2 


\begin{tabular}{|c|c|c|c|c|}
\hline Materials & Composition* & Batch $n^{\circ}$ & Validity & Manufacturer \\
\hline $\begin{array}{c}\text { Vitrebond }^{\mathrm{TM}} \\
\text { Light Cure Glass } \\
\text { Ionomer Liner/Base }\end{array}$ & $\begin{array}{c}\text { Powder: } \\
\text { Fluoro-aluminosilicate } \\
\text { glass } \\
\text { Liquid: } \\
\text { Acrylic acid copolymer } \\
\text { containing pendant } \\
\text { methacryloxy groups, } \\
\text { HEMA }\end{array}$ & 20080318 & $2010-2012$ & $\begin{array}{c}\text { 3MESPE } \\
\text { Dental Products, St. } \\
\text { Paul, MN, USA }\end{array}$ \\
\hline $\begin{array}{c}\text { Filtek }^{\mathrm{TM}} \text { Z250 } \\
\text { Universal } \\
\text { Restorative }^{\circledR} \text { - Shade } \\
\text { A3 }\end{array}$ & $\begin{array}{c}\text { Bis-GMA, UDMA, Bis- } \\
\text { EMA, TEGDMA } \\
\text { Zirconium/silica }\end{array}$ & N 107490 & $2012-06$ & $\begin{array}{c}\text { 3MESPE } \\
\text { Dental Products, St. } \\
\text { Paul, MN, USA }\end{array}$ \\
\hline $\begin{array}{c}\text { Adper }^{\mathrm{TM}} \\
\text { Single Bond } 2^{\circledR}\end{array}$ & $\begin{array}{l}\text { Bis-GMA, HEMA, } \\
\text { Dimethacrylates } \\
\text { Methacrylied } \\
\text { polyalkenoic acid } \\
\text { copolymers } \\
\text { Photoinitiador } \\
\text { Water + Ethanol }\end{array}$ & 8RM & $2011-05$ & $\begin{array}{c}\text { 3MESPE } \\
\text { Dental Products, St. } \\
\text { Paul, MN, USA }\end{array}$ \\
\hline Phosphoric acid ${ }^{\circledR}$ & Phosphoric acid $37 \%$ & 145017B & $2012-08$ & $\begin{array}{c}\text { Dentsply } \\
\text { Rio de Janeiro, RJ, } \\
\text { Brazil }\end{array}$ \\
\hline Rhodamine $\mathrm{B}^{\circledR}$ & $\begin{array}{c}\mathrm{C}_{28} \mathrm{H}_{31} \mathrm{CIN}_{2} \mathrm{O}_{3} \\
\mathrm{MM}=479.02 \mathrm{~g} / \mathrm{mol}\end{array}$ & 33907062 & $2013-06$ & $\begin{array}{c}\text { Sigma - Aldrich } \\
\text { Chemie GmbH, } \\
\text { Gillingam, New Rd, } \\
\text { UK }\end{array}$ \\
\hline
\end{tabular}

${ }^{*}$ According to manufacturers' technique profiles.

BisGMA- bisphenol A diglycidyl methacrylate; UDMA - urethane dimethacrylate; Bis-EMA - ethoxylated bisphenol-A dimethacrylate; TEGDMA - triethyleneglycol-dimethacrylate; HEMA; 2-hydroxyethyl methacrylate

Figure 1- Materials used in this study

was mixed with a fluorescent reagent (Rhodamine B, Sigma-Aldrich ChemieGmbH, Gillingham, UK) in a concentration of $0.16 \mathrm{mg} / \mathrm{Ml}^{6}$, before being used.

The remaining slices were sectioned mesiodistally into sticks. Three to four sticks were obtained from each tooth, with a cross-sectional area of approximately $0.8 \mathrm{~mm}^{2}$. Microtensile test was performed in a Universal Testing Machine (EMIC DL 500 BF, São José dos Pinhais, PR, Brazil) at a crosshead speed of $0.5 \mathrm{~mm} / \mathrm{min}$ (Figure 2). After testing, the specimens were carefully removed and the cross-sectional area at the site of fracture measured with a digital caliper (Mitutoyo Digmatic Caliper, Mitutoyo Sul Americana, Rio de Janeiro, RJ, Brazil) to calculate the tensile bond strength in MPa.

Both surfaces of each fracture site were observed in a stereomicroscope (Leica MZ6, Mannheim, Germany) with 40x magnification for analysis of failure mode. Mode failure was classified into four types: adhesive, cohesive in dentin, cohesive in resin composite and mixed failure.

Since a normal distribution was observed for the bond strength values of all groups, data were analyzed by two-way analysis of variance (ANOVA). The presence of gaps were analyzed by Fisher test. Both tests were performed at the significance level of $5 \%$.
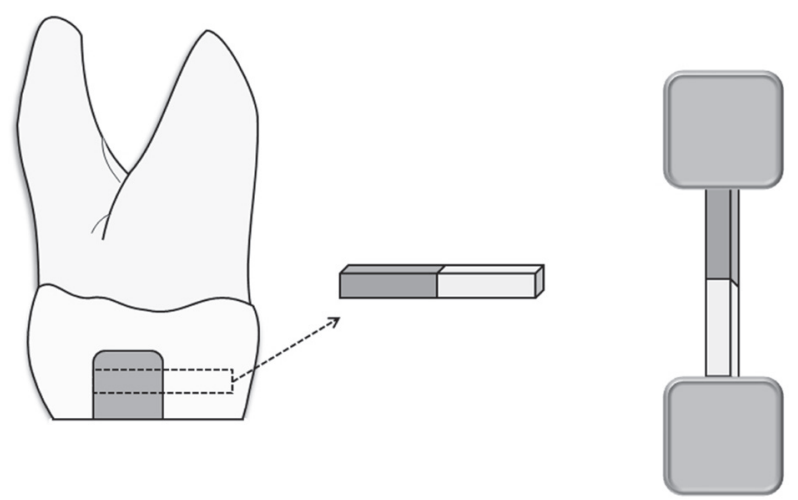

Figure 2- Schematic representation of beams preparation 


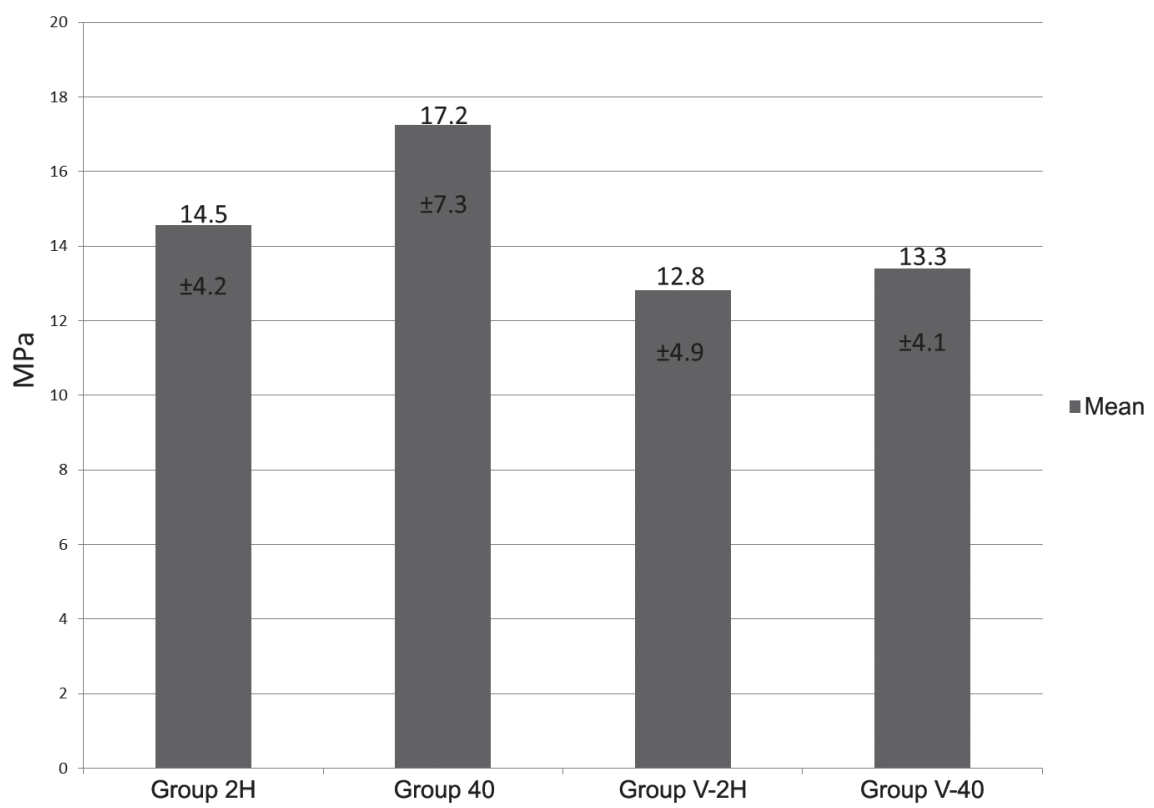

Figure 3- Mean (standard deviations) of microtensile bond strength (MPa) to dentin

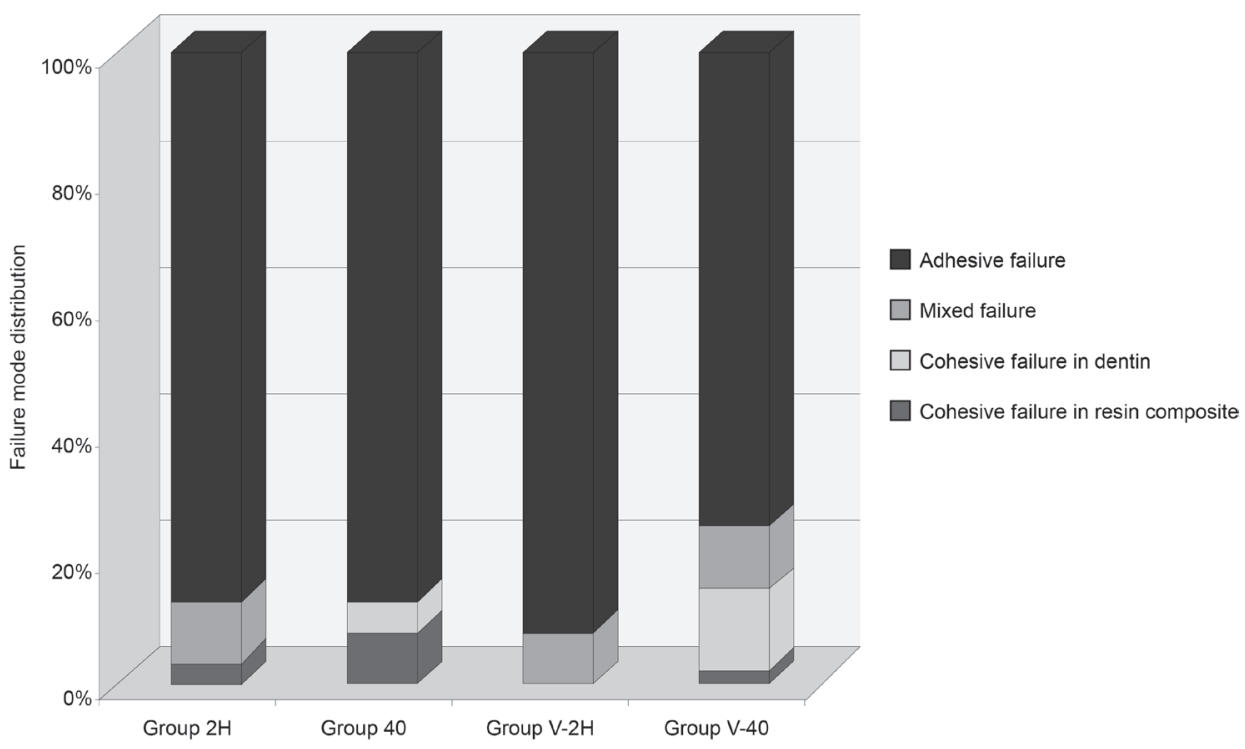

Figure 4- Failure mode distribution (\%)

\section{RESULTS}

Means and standard deviations of the bond strength ( $\mathrm{MPa}$ ) are summarized in Figure 3. There was no difference in microtensile bond strength to dentin between groups with or without resinmodified glass-ionomer cement lining $(p=0.063)$ and between the different composite layering technique $(p=0.272)$. No interaction between these factors were observed $(p=0.476)$.

The analysis of the mode of fracture revealed $87 \%$ of adhesive failures for group $2 \mathrm{H}, 87 \%$ for group $40,91 \%$ for group $\mathrm{V}-2 \mathrm{H}$ and $75 \%$ for group V-40 (Figure 4).

Regarding the presence of gap at the interface dentin/resin, no statistical significant difference among groups $(p>0.05)$ was observed. The presence of gaps (Figure 5) was observed in groups $2 \mathrm{H}$ (1 gap), $\mathrm{V}-2 \mathrm{H}$ (3 gaps) and $\mathrm{V}-40$ (2 gaps).

\section{DISCUSSION}

Most of the bond strength studies are performed using dentin pulp floor or axial walls as substrate. Studies on flat dentin surfaces are far from clinical reality, since they do not take into account the stress generated in cavity geometry ${ }^{9}$. In the present study, Class I cavities (high C-factor) were prepared in dentin, allowing the most negative potential of this cavities and clinical reality. The aim of this study 


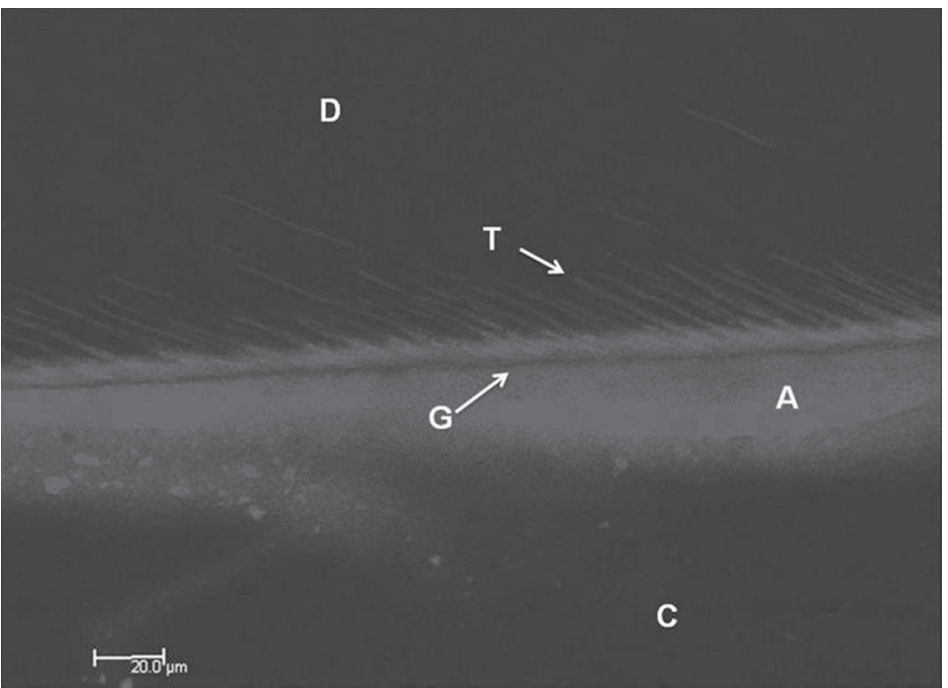

Figure 5- Representative Confocal Laser Scanning Microscopy (CLSM) of bonded interface with presence of gaps ( $D=$ Dentin; T=Resin Tag; G=Gap; A=Adhesive; $C=$ Resin composite)

was to determine the influence of these factors on the lateral walls of cavity, since marginal interface is the fragile point of composite restoration.

A resilient material with lower modulus of elasticity than resin composite is indicated as a liner due to its capability to absorb the stress originated at the adhesive interface during shrinkage polymerization ${ }^{2,30}$. Glass-ionomer cements have been reported to reduce this stress, improving marginal sealing and decreasing gap formation and microleakage at the dentin/resin composite adhesive interface $2,7,27,34$. While others authors showed that the use of resin-modified glass-ionomer liners does not seem to improve the immediate bond strength of a resin composite to the lateral cavity walls of occlusal restorations ${ }^{27}$ and did not contribute to increase bond strength ${ }^{11}$ or decrease internal gap formation ${ }^{25}$. In our study, the use of resin-modified glass-ionomer lining did not affect the bond strength and gap formation at the lateral walls of a Class I type cavity. This might be happening due to the incomplete shrinkage of glass-ionomer cement during the first minutes of treatment ${ }^{2}$. Therefore, flow of the material may still proceed during the stage the bond gained strength.

The insertion of increments allows a better adaptation of resin composite ${ }^{23}$. In small cavities, the bond strength to cavity floor is not affected by the filling technique, however, in large sized cavities, a high C-factor $(=5)$ is risky for bonding ${ }^{15}$, in which the incremental technique increased the microtensile bond strength to the cavity floor compared to the bulk filling technique.

Incremental technique (with layers less than $2 \mathrm{~mm}^{2}$ thick) appears to not influence the bond strength $^{27}$ and two main hypotheses were raised to explain this performance: 1) the incremental technique allows a balance with low stress values;
2) polymerization would be more uniform and efficient through the composite's entire thickness. In this study, the composite layering technique was also not a significant factor.

Cuspal deflection in the incremental filling technique was lower than in the bulk filling technique, and there is no significant difference between horizontal and oblique incremental filling techniques ${ }^{24}$. The same can be observed in bond strength ${ }^{16}$.

The layering technique in large Class I cavities increased the bond strength of resin composite in lateral cavity walls, in push-out test ${ }^{10}$. In addition, the high failure rate in the high C-factor Class I cavity, associated with polymerization shrinkage and shrinkage stress, were not observed in the layering technique, indirect curing of the resin composite or when a resin-modified glass-ionomer was used as a liner ${ }^{31}$.

Despite the controversy about the advantages of using a resin-modified glass-ionomer cement lining to minimize postoperative pain and marginal sealing ${ }^{19}$ and the mode of insertion of the resin composite, it is not yet clear if these strategies are effective in decreasing the influence of the $\mathrm{C}$-factor by dissipating shrinkage stress. Moreover, total elimination of microleakage and gaps, mainly in lateral walls, has yet to be reported.

\section{CONCLUSION}

The use of resin-modified glass-ionomer cement lining and the composite layering insertion technique of resin composite did not affect bond strength and gap formation at the adhesive interface of dentinal lateral walls of occlusal restorations. Thus, the hypothesis tested must be rejected. 


\section{REFERENCES}

1- Abbas G, Fleming GJ, Harrington E, Shortall AC, Burke FJ. Cuspal movement and microleakage in premolar teeth restored with a packable composite cured in bulk or in increments. J Dent. 2003;31:437-44.

2- Alomari QD, Reinhardt JW, Boyer DB. Effect of liners on cusp deflection and gap formation in composite restorations. Oper Dent. 2001;26:406-11

3- Arhun N, Celik C, Yamanel K. Clinical evaluation of resin-based composites in posterior restorations: two-year results. Oper Dent. 2010;35:397-404.

4- Bernardo $M$, Luis $H$, Martin $M D$, Leroux BG, Rue $T$, Leitão J, et al. Survival and reasons for failure of amalgam versus composite posterior restorations placed in a randomized clinical trial. J Am Dent Ass. 2007;138:775-83.

5- Bicalho AA, Valdívia AD, Barreto BC, Tantbirojn D, Versluis $A$, Soares $C$ J. Incremental filling technique and composite material - part II: shrinkage and shrinkage stresses. Oper Dent. 2014;39:E83-92.

6- D'Alpino PH, Pereira JC, Svizero NR, Rueggeberg FA, Pashley $\mathrm{DH}$. Use of fluorescent compounds in assessing bonded resinbased restoration: a literature review. J Dent. 2006;34:623-34.

7- Davidson CL, de Gee AJ, Feilzer AJ. The competition between the composite-dentin bond strength and the polymerization contraction stress. J Dent Res. 1984;63:1396-9.

8- De Munck J, Van Landuyt K, Coutinho E, Poitevin A, Peumans $M$, Lambrechts $P$, et al. Micro-tensile bond strength of adhesives bonded to Class-I cavity-bottom dentin after thermo-cycling. Dent Mater. 2005;21:999-1007

9- Feilzer AJ, De Gee AJ, Davidson CL. Setting stress in composite resin in relation to configuration of the restoration. J Dent Res. 1987;66:1636-9.

10- Félix SA, González-Lópes S, Mauricio PD, Aguilar-Mendoza JA, Bolanos-Carmoña. Effects of filling techniques on the regional bond strength to lateral walls in Class I cavities. Oper Dent. 2007;32:602-9.

11- Figueiredo Reis A, Giannini M, Ambrosano GM, Chan DC. The effects of filling techniques and low-viscosity composite liner on bond strength to class II cavities. J Dent. 2003;31:59-66.

12- Fleming GJ, Cara RR, Palin WM, Burke FJ. Cuspal movement and microleakage in premolar teeth restored with resin-based filling materials cured using a "soft-start" polymerization protocol. Dent Mater. 2007;23:637-43.

13- Going RE. Microleakage around dental restorations: a summarizing review. J Am Dent Assoc. 1972;84:1349-57.

14- He Z, Shimada Y, Sadr A, Ikeda M, Tagami J. The effects of cavity size and filling method on the bonding to Class I cavities. J Adhes Dent. 2008;10:447-53.

15- He Z, Shimada Y, Tagami J. The effects of size and incremental technique on micro-tensile bond strength of resin composite in Class I cavities. Dent Mater. 2007;23:533-8.

16- Jafarpour S, El-Badrawy W, Jazi HS, McComb D. Effect of composite insertion technique on cuspal deflection using an in vitro simulation model. Oper Dent. 2012;37:299-305.

17- Jang JH, Park SH, Hwang IN. Polymerization shrinkage and depth of cure of bulk-fill resin composites and highly filled flowable resin. Oper Dent. 2015;40:172-80.
18- Kakaboura A, Rahiotis C, Watts D, Silikas N, Eliades G. $3 \mathrm{D}$-marginal adaptation versus setting shrinkage in light-cured microhybrid resin composites. Dent Mater. 2007;23:272-8.

19- Kidd EA. Microleakage: a review. J Dent. 1976;4:199-206.

20- Kim RJ, Kim YJ, Choi NS, Lee IB. Polymerization shrinkage, modulus, and shrinkage stress related to tooth-restoration interfacial debonding in bulk-fill composites. J Dent. 2015;43:4309.

21- Krejci I, Lutz F, Krejci D. The influence of different base materials on marginal adaptation and wear of conventional Class II composite resin restorations. Quintessence Int. 1988;19:191-8. 22- Kwon Y, Ferracane J, Lee IB. Effect of layering methods, composite type, and flowable liner on the polymerization shrinkage stress of light cured composites. Dent Mater. 2012;28:801-9.

23- Nikolaenko SA, Lohbauer U, Roggendorf M, Petschelt A, Dasch W, Frankenberger R. Influence of c-factor and layering technique on microtensile bond strength to dentin. Dent Mater. 2004;20:579-85.

24- Park J, Chang J, Ferracane J, Lee IB. How should composite be layered to reduce shrinkage stress: incremental or bulk filling? Dent Mater. 2008;24:1501-5.

25- Peliz MI, Duarte S Jr, Dinelli W. Scanning electron microscope analysis of internal adaptation of materials used for pulp protection under composite resin restorations. J Esthet Restor Dent. 2005;17:118-28.

26- Sakaguchi RL, Peters MC, Nelson SR, Douglas WH, Poort HW. Effects of polymerization contraction in composite restorations. J Dent. 1992;20:178-82.

27- Sampaio PC, Almeida Júnior AA, Francisconi LF, Casas-Apayco LC, Pereira JC, Wang L, et al. Effect of conventional and resinmodified glass-ionomer liner on dentin adhesive interface of Class I cavity walls after thermocycling. Oper Dent. 2011;36:403-13. 28- Soares CJ, Bicalho AA, Tantbirojn D, Versluis A. Polymerization shrinkage stresses in a premolar restored with different composite resins and different incremental techniques. J Adhes Dent. 2013;15:341-50.

29- Soncini JA, Maserejian NN, Trachtenberg F, Tavares M, Hayes C. The longevity of amalgam versus compomer/composite restorations in posterior primary and permanent teeth: findings from the New England Children's Amalgam Trial. J Am Dent Assoc. 2007; $138: 763-72$

30- Tolidis K, Nobecourt A, Randall RC. Effect of a resin-modified glass ionomer liner on volumetric polymerization shrinkage of various composites. Dent Mater. 1998;14:417-23.

31- Van Dijken JW. Durability of resin composite restorations in high C-fator cavities: a 12-years follow-up. J Dent. 2010;38:46974.

32- Van Dijken JW, Pallesen U. A randomized controlled three year evaluation of "bulk-filled" posterior resin restorations based on stress decreasing resin technology. Dent Mater. 2014;30:e245-51. 33- Van Ende A, Van de Casteele E, Depypere M, De Munck J, Li $X$, Maes $F$, et al. 3D volumetric displacement and strain analysis of composite polymerization. Dent Mater. 2015;31:453-61. 34- Wattanawongpitak N, Yoshida T, Burrow MF, Tagami J. The effect of thermal stress on bonding durability of resin composite adaptation to the cavity wall. Dent Mater J. 2007;26:445-50. 